\title{
CONTEXTUALIZAÇÃO E INTERDISCIPLINARIDADE: REVISANDO CONCEITOS E APLICAÇÕES NO ENSINO DE FÍSICA E CIÊNCIAS
}

\section{CONTEXTUALIZATION AND INTERDISCIPLINARITY: REVIEWING CONCEPTS AND APPLICATIONS IN PHYSICS AND SCIENCES TEACHING}

\author{
Francisco Carlos Rocha Fernandes ${ }^{1}$ \\ Alan Prestes ${ }^{2}$
}

Resumo: O ensino da disciplina de Física se baseia, muitas vezes, na apresentação dos conteúdos, conceitos e leis físicas de forma mecânica e fragmentada, além de distanciada das experiências e vivências prévias dos alunos. Em oposição a essa realidade, os documentos oficiais, que norteiam a educação no país, como os Parâmetros Curriculares Nacionais (PCN), apontam, entre outras concepções metodológicas, a contextualização e a interdisciplinaridade do conhecimento como abordagens educacionais facilitadoras de uma aprendizagem, na qual, educadores e alunos são agentes ativos na construção do conhecimento. Neste artigo, é apresentada uma revisão da literatura dos conceitos de contextualização e interdisciplinaridade no ensino de Física do Ensino Médio e de Ciências no Ensino Fundamental, com o objetivo de melhor entender seu importante papel nas propostas e ações de ensino-aprendizagem, que privilegiam um conhecimento contextualizado e integrado à vida do educando. Relatos de experiências bem-sucedidas na adoção destas concepções são também apresentados e comentados.

Palavras-chave: Ensino de Física. Contextualização. Interdisciplinaridade.

Abstract: The teaching of Physics is often based on the presentation of contents, concepts and physical laws in a mechanical and fragmented way, in addition to that, it is distant the students' previous experiences. In opposition to this reality, official documents, which guide education, such as the National Curriculum Parameters (PCN), point out, among other methodological concepts, the contextualization and interdisciplinarity of knowledge as educational approaches that facilitate learning, in which educators and students are active agents in the construction of their own knowledge. In this article, a review from de literature about the concepts of contextualization and interdisciplinarity in the context of Physics teaching in High School and Science in Elementary School, is presented, with the aim of better understand their important role in the proposals and actions of teaching-learning, which privilege contextualized knowledge and integrated to the student's life. Reports of successful experiences in adopting these concepts are also presented and commented on.

Key words: Physics teaching. Contextualization. Interdisciplinarity.

Data de submissão: 15.05 .2021

Data de aprovação: 03.08.2021

\footnotetext{
1 Doutor em Ciência Espacial. Docente no Instituto Federal de Educação, Ciência e Tecnologia de São Paulo - Campus São José dos Campos (IFSP-SJC), E-mail: fcrochafernandes@gmail.com.

2 Pesquisador do Laboratório de Física e Astronomia do Instituto de Pesquisa e Desenvolvimento (IP\&D) da Universidade do Vale do Paraíba - Univap, E-mail: aprestes@gmail.com.
} 
Identificação e disponibilidade:

(https://revista.univap.br/index.php/revistaunivap/article/view/2623, http://dx.doi.org/10.18066/revistaunivap.v27i55.2623).

\section{INTRODUÇÃO}

Muitas vezes, o ensino da Física no Ensino Médio (e Ciências no Ensino Fundamental) nas escolas se baseia na apresentação dos conteúdos, conceitos e leis físicas de forma fragmentada e pela fixação pela repetição, pela automatização ou memorização, quase sempre distanciada das experiências e da sua identificação nos fenômenos do dia a dia dos alunos.

O ensino formal da Física é muitas vezes caracterizado pela mera apresentação dos conteúdos, conceitos e leis físicas de maneira fragmentada e distanciada das experiências vivenciadas pelos alunos no seu cotidiano. Geralmente, os modelos para os conceitos físicos que os alunos trazem para a sala de aula não coincidem com os modelos científicos e, portanto, na visão do alunado, o ensino formal é ausente de significação.

Para Nascimento (2010), o ensino da Física não se apresenta adequado na forma e também no conteúdo, pois se mostra como um estereótipo como do conhecimento absoluto e estabelecido, não procurando mostrar a relatividade dos fatos e a correlação entre eles. Desta forma, uma abordagem que prioriza apenas a teoria e a abstração, pode produzir um distanciamento entre os conteúdos ministrados em sala de aula e sua identificação nos fenômenos do dia a dia dos alunos.

Portanto, uma abordagem que reforce experiências e ações pedagógicas baseadas na percepção dos conceitos físicos pela associação de sua ocorrência na natureza, por exemplo, caracterizada por uma proposta de ensino contextualizada/interativa pode contribuir para uma aprendizagem e na construção do conhecimento.

O ensino da Física deve promover um diálogo entre as ideias pré-concebidas dos alunos e as ideias científicas ministradas em sala de aula (BARBOSA et al., 2010). Não deve privilegiar a fixação de conceitos pela repetição de exercícios puramente procedimentais, pela automatização ou memorização, mas favorecer experiências e ações pedagógicas baseadas na percepção dos conceitos físicos pela associação de sua ocorrência na natureza, favorecendo um aprendizado alicerçado na construção do conhecimento. A ineficiência do ensino, apontado em avaliações, pode não representar um despreparo de professores ou de condições escolares inadequadas, mas sim uma deficiência metodológica.

Em oposição a este modelo tecnicista, que, segundo Fernandes (2007), apresenta-se até os dias de hoje desvinculado do cotidiano dos alunos e com a finalidade apenas de instrução do conteúdo, propostas curriculares inovadoras têm surgido, baseadas em uma concepção que prioriza o papel investigativo do aluno no processo de ensino e aprendizado. Destaca-se a necessidade de discutir e propor metodologias e ações pedagógicas que visem à melhoria do ensino da Física no ambiente escolar, na tentativa de aprimorar e consolidar a aprendizagem.

O principal questionamento que motivou a pesquisa pode ser sintetizado na seguinte questão: "Qual o papel desempenhado pela contextualização e pela interdisciplinaridade no ensino de conteúdos de Física para o Ensino Médio ou Ciências para o Ensino Fundamental? ".

Com base nestes questionamentos, o principal objetivo da pesquisa é a conceituação destes termos, contextualização e interdisciplinaridade, no ambiente 
educacional, e o estudo e a discussão de abordagens de ensino que incorporam a contextualização, principalmente focadas nas experiências cotidianas do alunado, considerando o caráter interdisciplinar da Física e dos fenômenos naturais ligados às diversas áreas das ciências naturais, correlatas da Física, e como elas podem contribuir para uma aprendizagem mais significativa.

\section{REVISÃO DA LITERATURA}

A análise dos trabalhos do levantamento bibliográfico, realizado por meio da revisão da literatura, abordando a contextualização e a interdisciplinaridade de conteúdos no ensino, em particular no ensino de Física, é apresentada e discutida nas seções a seguir. Muitos dos trabalhos pesquisados definem os conceitos de contextualização e interdisciplinaridade a partir de referências a documentos oficiais dos órgãos de Educação, de modo que, optou-se por dar mais ênfase a essas conceituações. Assim, os trabalhos pesquisados foram agrupados em referências de documentos oficiais da educação, como os Parâmetros Curriculares Nacionais do Ensino Médio (PCNEM), as Orientações Curriculares para o Ensino Médio, entre outros e os trabalhos que conceituam essas abordagens com um viés mais teórico e abrangente. Por fim, são apresentados e discutidos trabalhos que tratam destes temas no contexto do ensino da Física ou Ciências, incluindo relatos de experiência e estudos de caso.

Os conceitos de contextualização e interdisciplinaridade no ensino, muitas vezes são abordados de forma não dissociada. De acordo com as Bases Legais dos PCNEM (MEC, 2000a), a contextualização e a interdisciplinaridade são conceitos que se destacam como os dois princípios pedagógicos fundamentais para o exercício da docência visando à construção de competências do educando. Estes conceitos são conceituados nas seções a seguir.

\subsection{CONCEITUANDO CONTEXTUALIZAÇÃO}

O Dicionário Interativo da Educação Brasileira (DIEB, 2020), define contextualização como "o ato de vincular o conhecimento à sua origem e à sua aplicação", sendo que a ideia de contextualização passou a ser considerada a partir da reforma do Ensino Médio, e da Lei de Diretrizes e Bases. Por sua vez, a Interdisciplinaridade é um conceito amplo definido como "perspectiva de articulação interativa entre as diversas disciplinas no sentido de enriquecê-las através de relações" (DIEB, 2020).

A adoção da contextualização como princípio de organização curricular visa facilitar a atividade docente a partir da percepção e da experiência individual de cada estudante e, portanto, facilitar o processo de aprendizagem dos conhecimentos e conceitos abstratos presentes no currículo escolar. A contextualização remete à conexão entre diferentes aspectos da vida do aluno e aos conteúdos que lhe é passado na escola, facilitando o paralelo entre teoria e prática. Pode ser entendida como um recurso para tornar a aprendizagem significativa ao relacioná-la às experiências da vida cotidiana ou com os conhecimentos adquiridos prévia e espontaneamente (MEC, 2002).

O conhecimento contextualizado, segundo os PCNEM (MEC, 2000a), representa uma ferramenta ou uma estratégia pedagógica que pode contribuir para colocar o aluno como agente ativo no processo de ensino, aquele que contribui na construção 
do seu próprio conhecimento. Nesta mesma linha, as Orientações Curriculares para o Ensino Médio (MEC, 2006) propõem que a contextualização pode proporcionar alternativas para que o aluno sinta a necessidade de buscar e compreender cada novo conhecimento abordado e adquirido, possibilitando, assim, problematizar a realidade do aluno, extraí-la do seu contexto e projetá-la para a abordagem dos conteúdos. Neste sentido,

(...) a contextualização no ensino de ciências abarca competências de inserção da ciência e de suas tecnologias em um processo histórico, social e cultural e o reconhecimento e discussão de aspectos práticos e éticos da ciência no mundo contemporâneo (MEC, 2002, p.31).

As Orientações Curriculares para o Ensino Médio (MEC, 2006) pregam que não se pretende com a contextualização, partir do que o aluno já sabe e chegar ao conhecimento científico. O que se pretende é partir da reflexão crítica ao senso comum e proporcionar alternativas para que o aluno sinta a necessidade de buscar e compreender cada novo conhecimento abordado e adquirido. Como recurso didático, a contextualização permite problematizar a realidade do aluno, extraí-la do seu contexto e projetá-la para a análise, em outras palavras, contribui na elaboração de uma representação do mundo para sua melhor compreensão (MEC, 2006).

Contextualizar conteúdos representa ressignificar os conteúdos estruturados presentes no currículo escolar, agregando a eles um novo significado, mais permanente, que é fruto da soma do conhecimento da própria vivência do aluno e do conhecimento transmitido no ambiente escolar.

Desta forma, pode-se dizer que o processo de assimilação do conhecimento é estabelecido apenas quando envolve uma relação entre sujeito e objeto, ou seja, de acordo com os PCNEM (MEC, 2002), deve se estabelecer sempre o diálogo entre o mundo do estudante e o mundo do conhecimento a ser apresentado, para que, deste vínculo resulte o aprendizado dos conteúdos. Por isso, geralmente, o conhecimento escolar é alicerçado em uma transposição didática, em que a linguagem desempenha um papel fundamental (MEC, 2002).

Uma apresentação aprofundada e detalhada e uma discussão crítica dos conceitos de contextualização e interdisciplinaridade na educação, em particular no ensino de Ciências é apresentada por Ricardo (2005), que enfatiza haver uma escassez de trabalhos versando sobre os vários aspectos de abordagens e propostas pedagógicas embasadas na contextualização e não na mera referência ao cotidiano do estudante.

De acordo com esse mesmo autor (RICARDO, 2010), relatos de abordagens que se baseiam na contextualização para o ensino de Física e Ciências são cada vez mais frequentes no discurso de professores e de educadores, cujas abordagens, geralmente, se valem do cotidiano dos alunos e de seu entorno como subsídio para a contextualização. De forma que a contextualização serve como elemento motivador do aprendizado. Porém, ainda não se pode afirmar que esta seja uma prática frequente no dia a dia das escolas. Para o autor,

(...) enfoques atribuídos à contextualização adentram no campo epistemológico. Entretanto, o problema da relação entre teoria e realidade é mais evidente. Os futuros professores, frequentemente, aprendem a estrutura formal da física, mas têm dificuldade em relacioná-la com o mundo real. Parece haver um abismo entre os saberes formais e a realidade. Em certa medida, isso se deve a um ensino excessivamente apoiado na resolução de problemas e exercícios, sem discussões conceituais. Para entender melhor essa relação entre teoria e realidade é preciso compreender que a ciência 
constrói modelos e, por conseguinte, modificam o real. (RICARDO, 2010, p. 35).

Para Wartha e Alário (2005), a aplicação da contextualização nas práticas pedagógicas vai além da simples exemplificação, envolve uma postura constante frente ao ensino, assim, nas palavras dos autores,

(...) contextualizar o ensino significa incorporar vivências concretas e diversificadas, e também incorporar o aprendizado em novas vivências. É assumir que todo conhecimento envolve uma relação entre sujeito e objeto (WARTHA; ALÁRIO, 2005, p. 43).

Esses autores acrescentam, sobre o conceito de contextualização, que:

(...) contextualizar é construir significados e significados não são neutros, incorporam valores porque explicitam o cotidiano, constroem compreensão de problemas do entorno social e cultural, ou facilitam viver o processo da descoberta (WARTHA; ALÁRIO, 2005, p. 43).

Por sua vez, Macedo (2013), reforçando a importância de uma abordagem contextualizada, menciona que muitos trabalhos acadêmicos, entre eles, Auler e Delizoicov (2001); Lopes, Gomes e Lima (2003); Ricardo (2005); Kato (2007); Santos (2007), vêm sendo publicados defendendo propostas contextualizadas como uma estratégia educacional de aproximação dos conteúdos ministrados na escola com a realidade do aluno, em uma perspectiva de esta forma venha agregar significado e eficiência nos processos de ensino significativo.

Sousa et al. (2013) destacaram que a abordagem de diferentes temas, trazidos para o espaço de discussão das aulas, contribui na proposta de um ensino contextualizado, e para a formação de alunos com visões mais críticas, como cidadãos. A contextualização pode ser alcançada, portanto, pela abordagem de diferentes temas, bem como pela proposição de situações-problema, sendo que a Física possui importantes mecanismos que facilitam a compreensão de problemas.

Considerando que dentre os referenciais que abordam o tema contextualização, os mais próximos de nós professores são os documentos oficiais (PCN, DCNEM, LDB). Neste trabalho, inspiramo-nos em Kato (2007) e Ricardo (2005) por se tratarem de autores que investigaram a contextualização a partir destes documentos.

Conforme sintetizado por Macedo (2013) a partir dos autores, citados acima, a contextualização pode ser caracterizada por quatro enfoques:

1 - contextualização como aproximação do conteúdo com o cotidiano do aluno;

2 - contextualização como a aproximação e relação entre conhecimentos de diversas áreas científicas de modo que possibilitem o trabalho interdisciplinar; 3 - contextualização como meio de relacionar aspectos socioculturais e históricos principalmente a partir das relações entre Ciência - Tecnologia e Sociedade; e

4 - contextualização como possível caminho a fim de minimizar os danos causados no processo de transposição didática. (MACEDO, 2013). 


\title{
2.2 CONCEITUANDO INTERDISCIPLINARIDADE
}

Muitos estudiosos abordam o conceito da interdisciplinaridade nas suas várias facetas, pedagógica, reflexiva, prática e conceitual. Entre esses autores, destaca-se Ivani C. A. Fazenda, que apresenta uma vasta bibliografia sobre o tema (FAZENDA, 1991a; 1991b; 1994; 1998; 2000; 2001; 2003; 2008; 2011a; 2011b). Segundo a autora,

\begin{abstract}
A interdisciplinaridade vem sendo utilizada como "panaceia" para os males da dissociação do saber, a fim de preservar a integridade do pensamento e o restabelecimento de uma ordem perdida. Antes que um "slogan", é uma relação de reciprocidade, de mutualidade, que pressupõe uma atitude diferente a ser assumida diante do problema do conhecimento, ou seja, é a substituição de uma concepção fragmentária para unitária do ser humano.
\end{abstract} (FAZENDA, 2011a).

O conceito de interdisciplinaridade se originou na década de 60 , em países como a França e a Itália, a partir de movimentos estudantis que pediam uma forma de ensino mais sintonizado com as questões sociais, políticas e econômicas da época, segundo Japiassu (1976). A interdisciplinaridade veio como uma resposta a essas manifestações, pelo fato que os grandes problemas da época não poderiam ser resolvidos por apenas uma disciplina ou uma única área do saber.

O conceito de interdisciplinaridade na educação chegou ao Brasil, no final da década de 1960, e rapidamente foi incorporado na elaboração da Lei de Diretrizes e Bases (LDB) e sua proposta tem sido intensificada nos PCN (FAZENDA, 2011b). No entanto, segundo a autora, embora desde então as reformas na educação brasileira mostrem cada vez mais a necessidade de adoção de abordagem interdisciplinar, ela ainda não é plenamente compreendida.

A proposta de interdisciplinaridade, de acordo com os mesmos PCNEM (MEC, 2000a), tem como objetivo a apresentação de maneira inter-relacionada ou interligada de diferentes áreas do conhecimento, o que contribui para uma aprendizagem mais significativa e permite agregar conhecimentos diversos na compreensão de conceitos e fenômenos e também na resolução de problemas. Assim, as orientações dos PCNEM para Ciências da Natureza, Matemática e suas Tecnologias do Ensino Médio (MEC, 2000b) são para a organização das disciplinas e visando a interdisciplinaridade e a contextualização, visto sua importância no aprendizado.

Os PCNEM (MEC, 2002) afirmam sobre o conceito de interdisciplinaridade:

(...) a interdisciplinaridade deve partir da necessidade sentida pelas escolas, professores e alunos de explicar compreender, intervir, mudar, prever, algo que desafia uma disciplina isolada e atrai a atenção de mais de um olhar, talvez vários (MEC, 2002).

Interdisciplinaridade, como uma prática pedagógica, não pode ser encarada como mera justaposição de disciplinas (MEC, 2006), refere-se à construção de um novo saber a respeito da realidade, a partir dos diversos saberes pré-existentes e disciplinares de cada área do conhecimento. $\mathrm{O}$ conceito de interdisciplinaridade pressupõe que cada conhecimento dialoga permanentemente com outros conhecimentos, sendo que este diálogo pode se estabelecer das mais diversas maneiras, seja por questionamentos, por comparações, por similaridades, confrontação, por identificação de manifestações distintas.

Segundo os PCNEM, 
Na perspectiva escolar, a interdisciplinaridade não tem a pretensão de criar novas disciplinas ou saberes, mas de utilizar vários conhecimentos de varias disciplinas para resolver um problema concreto ou compreender um determinado fenômeno sob diferentes pontos de vistas. Em suma, a interdisciplinaridade tem uma função instrumental. Trata-se de recorrer a um saber diretamente útil e utilizável para responder as questões e aos problemas sociais contemporâneos (MEC, 2002).

Nesta perspectiva de integração de diferentes áreas do conhecimento, é possível potencializar as condições necessárias para que haja um conhecimento motivador e um aprendizado mais significativo, despertando o aluno para obtenção de novos conhecimentos e capacitando-o a compreender e intervir na realidade, numa postura mais autônoma e menos distante da realidade (MEC, 2002).

Num aspecto teórico, uma proposta de interdisciplinaridade, representa uma abordagem conjunta entre teoria e prática, numa perspectiva de integração, numa concepção da totalidade. Para Frigotto (1995), a interdisciplinaridade é "uma necessidade relacionada à realidade concreta, histórica e cultural, constituindo-se assim como um problema ético-político, econômico, cultural e epistemológico".

No contexto de currículo escolar e das disciplinas, a interdisciplinaridade representa que as disciplinas operam e cooperam em conjunto, portanto, há uma interação entre as disciplinas ou áreas do saber. Dependendo do nível hierárquico dessa interação podem-se caracterizar os seguintes níveis de interação: multidisciplinaridade, pluridisciplinaridade, interdisciplinaridade transdisciplinaridade, como apresentados por Japiassu (1976) e Fazenda (2011a):

\begin{abstract}
Multidisciplinaridade: ocorre quando diferentes disciplinas estão presentes em um contexto, mas não existem relações diretas entre elas, onde as várias disciplinas não apresentam relação direta entre si.

Pluridisciplinaridade: ocorre quando diversas disciplinas são agrupadas em um mesmo nível hierárquico fazendo aparecer relações entre si, onde as disciplinas apresentam relações entre si.

Interdisciplinaridade: é um conjunto de disciplinas que se interagem entre si, apresentando um nível de hierarquia definida e tendo a noção de finalidade. Transdisciplinaridade: caracteriza um nível de interação superior à interdisciplinaridade, na qual ocorre uma interação de vários sistemas interdisciplinares aplicados em um contexto mais amplo, essas relações e interações estão presentes entre as diversas disciplinas, nos diferentes níveis hierárquicos.
\end{abstract}

Determinadas disciplinas apresentam, intrinsecamente, uma maior relação de proximidade ou identificação, por sua vez, outras disciplinas já se mostram maior distanciamento, seja pela abordagem e procedimentos envolvidos, seja pelo próprio objeto de estudo, ou mesmo pelo tipo de habilidades que mobilizam naquele que a investiga, conhece, ensina ou aprende. Para Bonatto et al. (2012),

(...) a interdisciplinaridade na escola complementa as disciplinas, criando no conceito de conhecimento uma visão de totalidade, onde os alunos possam perceber que o mundo onde estão inseridos é composto de vários fatores, que a soma de todos formam uma complexidade (BONATTO et al., 2012).

Os autores ainda complementam,

(...) um trabalho interdisciplinar, antes de garantir associação temática entre diferentes disciplinas, ação possível, mas não imprescindível, deve buscar unidade em termos de prática docente, ou seja, independentemente dos 
temas/assuntos tratados em cada disciplina isoladamente (BONATTO et al., 2012).

A interdisciplinaridade se manifesta quando os sujeitos envolvidos no processo de ensino e aprendizagem necessitam de procedimentos que se complementam e se inter-relacionam. Cabe ressaltar que a interdisciplinaridade supõe um eixo integrador que pode ser representado pelo objeto de conhecimento, ou uma proposta de investigação, uma estratégia de intervenção e, neste sentido, deve partir da necessidade dos atores no âmbito escolar.

\subsection{CONTEXTUALIZAÇÃO E INTERDISCIPLINARIDADE NO ENSINO DE FÍSICA E CIÊNCIAS}

Nesta seção, são apresentados diversos trabalhos pesquisados que abordam os temas da contextualização e da interdisciplinaridade, com um recorte mais aplicado, de implantação em propostas e ações pedagógicas e de resultados de pesquisas realizadas pelos autores envolvendo essa temática. Muitos trabalhos pesquisados abordam esse tema aplicado em diferentes áreas do conhecimento, e disciplinas escolares, tais como Química, Biologia, Pedagogia. No entanto, são apresentados apenas aqueles que se inserem no contexto do ensino da Física (para o Ensino Médio) e de Ciências (para o Ensino Fundamental).

De acordo com Silva (2004), antes de ser uma disciplina do currículo escolar, a Física é uma ciência, que visa compreender e estudar os mais variados fenômenos da natureza, buscando descobrir e discutir suas causas e seus efeitos, em particular, sua influência na vida do ser humano e na sua compreensão do mundo a seu redor. Portanto, é fundamental, que o ensino da Física, seja calcado em uma metodologia contextualizada/interativa que dê suporte às metodologias pedagógicas mais formais e tradicionais. Faz-se necessária a adoção de estratégias que garantam ao educando maior assimilação dos conceitos ensinados, por exemplo, por meio da sua associação com os fenômenos observados em seu próprio cotidiano.

Para Nascimento (2010), a contextualização dos conteúdos e a interdisciplinaridade podem proporcionar uma desmistificação do conhecimento científico, à medida que propõem um ensino de física que promova sua conexão com as causas e as consequências dos fenômenos físicos nas diversas áreas, mas principalmente, no entendimento do mundo real.

Nesse caso, a adoção de uma abordagem contextualizada da Física pode contribuir para assimilação dos conteúdos de forma mais eficiente, podendo tornar a disciplina mais prazerosa e favorecendo uma aprendizagem mais significativa. Trabalhos e estudos anteriores seguem esta metodologia, em particular contextualizando os conceitos físicos (teoria) a partir de fenômenos naturais ligados à Astronomia.

Mota, Bonomini e Rosado. (2009) relatam uma abordagem inovadora para o ensino informal de Física do Ensino Médio com inclusão de temas de Astronomia, realizada na Universidade Federal de Itajubá (UNIFEI), na forma de um curso de extensão para alunos do ensino médio. das redes pública e particular do município de Itajubá, MG. O curso, intitulado "Astronomia: Uma Nova Visão da Física do Ensino Médio", foi criado em 2005, por iniciativa de estudantes de Física (Licenciatura e Bacharelado) da UNIVFEI, com o apoio de docentes e coordenadores, sendo sua primeira edição realizada com 50 estudantes.

Mees (2004) e Mess e Steffani (2005) também apontam a Astronomia como um 
tema motivador do ensino de Física no Ensino Fundamental Os autores descrevem detalhes da proposta e da aplicação de atividades conceituais (sem ferramental matemático) relacionadas ao tema astronomia em turmas de $8^{\mathrm{a}}$ série (atualmente 90. ano) do Ensino Fundamental II, de uma Escola Estadual de Educação Básica de Goiás, na cidade de Santa Cruz do Sul, RS, e ressaltam os resultados positivos referentes a motivação, avaliação das aulas e participação dos discentes envolvidos.

Nessa mesma linha, quanto a abordar conteúdos da Física do ensino médio a partir de contextualização de fenômenos da natureza, mais especificamente de fenômenos naturais ligados à Astronomia, estão os trabalhos desenvolvidos por Fernandes et al. (2011; 2012a; 2012b) relacionados ao Subprojeto de Física do Programa Institucional de Iniciação à Docência (PIBID), desenvolvido na Universidade do Vale do Paraíba - UNIVAP.

Castro (2000) apresenta detalhadamente a aplicação contextualizada de vários tópicos ligados à Mecânica e à Óptica em aulas de Física para estudantes do Ensino Médio. O autor apresenta as ferramentas utilizadas, com o intuito de tornar as aulas mais acessíveis aos alunos, tendo como base a contextualização de conteúdos físicos relacionando-os a fenômenos naturais, tais como fenômenos ópticos, como eclipses, arco-íris, coloração do céu. De acordo com o autor, os resultados obtidos foram muito positivos, no sentido de contribuir para aumentar o interesse dos alunos para as aulas de Física, em particular aqueles que, notadamente, não se apresentavam motivados para a disciplina (CASTRO, 2000).

Macedo (2013) e Macedo e Silva (2014) apresentam uma investigação com licenciandos de Física da Universidade Federal de Itajubá sobre sua compreensão a respeito dos processos de contextualização no ensino da Física. Os resultados, de acordo com os autores apontam que os processos de contextualização mais relevantes identificados podem ser separados em: aproximação com o cotidiano, ensino significativo, relação interdisciplinar e alcance da denominada Alfabetização Científica e Tecnológica (ACT). Na fala da autora,

\begin{abstract}
O conceito de contextualização pode assumir diferentes interpretações que podem ir desde uma simples aproximação do conteúdo com o cotidiano do aluno - assumindo cotidiano apenas como experiências próximas à realidade do aluno e suas atividades rotineiras - até o entendimento de que o conteúdo deve ser trabalhado abordando além dos conceitos, aspectos históricos/socioculturais de forma crítica a fim de que o estudante compreenda que o conhecimento científico não é fragmentado ou disciplinar como aparece na grade escolar, e que sua relevância pode ser aplicada em diferentes contextos de significação (MACEDO, 2013).
\end{abstract}

Kato e Kawasaki (2011) apresentam resultados de uma pesquisa sobre diferentes concepções de contextualização do ensino encontradas com base em documentos curriculares oficiais e em professores Ciências e Biologia. Os autores também discutem as implicações pedagógicas dessas concepções para a organização do trabalho docente. Apesar de identificada uma multiplicidade de concepções de contextualização do ensino, elas não são contraditórias ou conflitantes entre si, pois todas, nas palavras dos autores,

(...) contextualizar é articular ou situar o conhecimento específico da disciplina (parte) a contextos mais amplos de significação (todo), estes, sim, bastante variados: o cotidiano do aluno, a(s) disciplina(s) escolar(es), a ciência (referência), o ensino e os contextos histórico, social e cultural (KATO; KAWASAKI, 2011). 
Um trabalho interessante, que não aborda diretamente revisão dos conceitos ou de propostas de contextualização e interdisciplinaridade no ensino, mas investiga o perfil das questões de Ciências Naturais aplicadas na prova do Exame Nacional do Ensino Médio (Enem) de 2011 e seu caráter interdisciplinar ou contextualizado é apresentado por Stadler e Hussein (2017). Os resultados da pesquisa apontam que há incongruências com o que era esperado, com relação ao perfil das questões em relação à interdisciplinaridade e contextualização em comparação com a literatura, pois a maioria das questões apresenta caráter disciplinar e não interdisciplinar. Os autores acrescentam ainda, que tais resultados, podem desmotivar a adoção de abordagens interdisciplinares, contrariando o preconizam os PCN.

Foi realizado um levantamento sobre a percepção de alunos do Ensino Médio sobre seu entendimento de conceitos ligados à Física, em particular o conceito de como pressão, por Freitas e Halmenschlager (2015) tendo como contexto o funcionamento do corpo humano. O objetivo foi investigar e discutir as potencialidades e os limites de uma abordagem contextualizada no ensino de Física tendo como base o corpo humano. As autoras relatam que os alunos demonstraram uma melhora significativa nas atividades experimentais contextualizadas desenvolvidas, mesmo entre aqueles que inicialmente apresentavam maior dificuldade de estabelecer relações entre o conceito físico de pressão e o funcionamento do corpo humano. Destacam ainda que, pelas falas dos alunos envolvidos, esses avaliaram que a abordagem teve papel facilitador para a compreensão dos conceitos físicos apresentados (FREITAS; HALMENSCHLAGER, 2015).

Outra proposta de atividade de contextualização de conteúdos físicos destinada a alunos do Ensino Médio é apresentada por Siqueira, Silva e Castro (2011). No caso, uma oficina prática para construção de um modelo simplificado de túnel de vento e com uso de outros recursos como vídeos de simulações de voo, visando ilustrar e explicar os processos de sustentação e controle de aeronaves, de forma a motivar aos estudantes a tentar estreitar a distância entre os conceitos e princípios físicos apresentados em sala de aula e sua representação no processo do voo. Além da contextualização, os autores destacam também o caráter interdisciplinar da abordagem, uma vez que podem ser explorados também aspectos da História e da Geografia, por exemplo.

Vizzotto, Mackedanz, Buss (2018) e Vizzotto e Mackedanz (2020) apresentam os resultados de uma pesquisa realizada, com base em entrevistas com alunos egressos do Ensino Médio, sobre suas percepções sobre a relação entre conteúdo da disciplina de Física e fenômenos físicos observados no dia a dia ligados ao trânsito. A pesquisa buscou medir, por meio de testes estatísticos, a possível conexão do grau de alfabetização científica com as aulas de Física que os participantes tiveram no Ensino Médio. A pesquisa apontou que muitas das dificuldades que os egressos tiveram na disciplina de Física no Ensino Médio estavam mais relacionadas à forma não contextualizada dos conteúdos, de modo que o ensino predominantemente expositivo/passivo acarretou, juntamente com dificuldades de assimilação dos conteúdos, maior desmotivação por parte do alunado. Esses resultados reforçam o papel das abordagens pedagógicas que abarcam a contextualização como um dos princípios norteadores do ensino.

A contextualização de conteúdos e a interdisciplinaridade do conhecimento, como revisado na revisão dos diversos trabalhos acadêmicos apresentados e discutidos, são dois pilares das propostas e práticas didático-pedagógicas de ensino, incluindo o ensino de Física e Ciências, que, se adotados de forma planejada e 
consciente, podem se revelar instrumentos bastante eficientes e úteis, para motivar e estimular os alunos para uma aprendizagem mais significativa.

Conforme brevemente exemplificado, pelos trabalhos citados, que representam apenas uma pequena amostra do vasto escopo de aplicações e propostas de contextualização dos conteúdos para o ensino de Física (e de Ciências), constata-se que as possibilidades de estratégias e ferramentas didático-pedagógicas que podem contribuir na implantação de práticas contextualizadas e interdisciplinares são muito numerosas.

Portanto, fica claro que a contextualização e a interdisciplinaridade se configuram como importantes alternativas metodológicas aliadas ao domínio do conhecimento docente, na busca de uma educação mais eficiente e com maior significação perante os alunos, particularmente no âmbito da conceituação física abordada em sala de aula.

\section{CONSIDERAÇÕES FINAIS}

Conforme apresentado e discutido, conclui-se que contextualização do conhecimento constitui uma ferramenta metodológica que se mostra, não apenas essencial, mas necessária, na estratégia pedagógica que contribui para modificar a atitude dos alunos, tidos como agentes passivos, em protagonistas no processo de ensino-aprendizagem, em particular no ensino da Física no Ensino Médio e também de Ciência no Ensino Fundamental. E para tanto, a contextualização, conforme pregada nos documentos oficiais sobre a educação, tem um potencial, considerandose a inserção dos conteúdos das disciplinas no contexto mais amplo do cotidiano do aluno e da percepção dos fenômenos da natureza, uma vez que a ciência, de modo geral, sempre desperta a curiosidade dos alunos.

Por outro lado, é praticamente um consenso entre gestores e educadores, que trabalhar com a interdisciplinaridade e a contextualização não é tarefa fácil, principalmente quando envolve uma mudança de paradigma, das metodologias tradicionais, por vezes já muito incorporadas no exercício da docência e face à resistência enfrenta por partes diversos segmentos do ambiente escolar. Também não é uma abordagem simples, de fácil adoção, pois muitas vezes representam um trabalho árduo para os professores envolvidos nesse processo, porque exige uma disposição pessoal para estudar os temas. Com certeza é um trabalho gratificante, principalmente se considerarmos os resultados positivos que essas ferramentas podem representar no aprendizado, e porque não dizer na vida dos alunos.

O presente trabalho de caráter revisional não tem a pretensão de completude sobre esta ampla temática da contextualização do conhecimento $\mathrm{e}$ da interdisciplinaridade como ferramentas pedagógicas. No entanto, é possível de face da pesquisa e análise do material bibliográfico, constatar que esse debate sobre a contextualização do conhecimento na educação, em particular no ensino de Física (e Ciências), não é tão recente. É possível também avaliar que a inserção deste tema nos debates e discussões no âmbito educacional tem crescido consideravelmente. Apenas para citar um exemplo, em trabalho de 2005, Ricardo (2005) mencionava a falta de discussão sobre o significado e sobre os processos da contextualização na educação, atribuindo essa escassez à falta de referenciais sobre o assunto na literatura. O mesmo autor, em trabalho cinco anos depois (RICARDO, 2010), afirma que os relatos de abordagens que baseados na contextualização para o ensino estão cada vez recorrentes no discurso dos educadores. 
Portanto, é importante concluir reforçando que esta temática, ainda mostra-se bastante relevante e ainda muito atual e merece discussão, visto que, de face das grandes dificuldades relatadas no ensino da Física, a adoção de práticas pedagógicas contextualizadas podem promover a aproximação e melhor assimilação por parte dos alunos dos conceitos físicos abordados em sala de aula.

\section{REFERÊNCIAS}

AULER, D.; DELIZOICOV, D. Alfabetização científico-tecnológica para quê? Ensaio: Pesquisa em Educação em Ciências, Belo Horizonte, v. 3, n. 1, p. 122-134, 2001. Doi: https://doi.org/10.1590/1983-21172001030203

BARBOSA, C. L. D. R. et al. Projeto Institucional PIBID/Univap: Universidade e Escola Pública: espaço de formação docente, PIBID. Edital 2010 Municipais e Comunitárias, CAPES, 2010. [S.I.:S.n.], 2010.

BONATTO, A. et al. Interdisciplinaridade no ambiente escolar. In: IX Seminário de pesquisa em educação da região Sul. In:SEMINÁRIO DE PESQUISA E EDUCAÇÃODA REGIÃO SUL, 9., 2012, Caxias do Sul. Anais[...]. Caxias do Sul: ANPED, 2012. Disponível em:

http://www.ucs.br/etc/conferencias/index.php/anpedsul/9anpedsul/paper/viewFile/241 4/501 Acesso em: 16 set. 2021.

CASTRO, R. C. A Contextualização da Física no Ensino Médio. 2000. Trabalho de Conclusão de Curso (Licenciatura em Física). Universidade Federal do Rio de Janeiro, Rio de Janeiro, 2000. Disponível em:

https://pantheon.ufrj.br/bitstream/11422/ 3098/5/RCCastro.pdf. Acesso em: 6 maio 2021.

DIEB - Dicionário Interativo da Educação Brasileira. Agência EducaBrasil. 2020. Disponível em: http://www.educabrasil.com. Acesso em: 12 abr. 2020.

FAZENDA, I. C. A. (org.). Práticas interdisciplinares na escola. São Paulo: Cortez, 1991a.

FAZENDA, I. C. A. Interdisciplinaridade: um projeto em parceria. São Paulo: Loyola, 1991b.

FAZENDA, I. C. A. Interdisciplinaridade: História, teoria e pesquisa. Campinas: Papirus, 1994.

FAZENDA, I. C. A. (org.). Didática e Interdisciplinaridade. São Paulo: Papirus, 1998.

FAZENDA, I. C. A. Integração como proposta de uma nova ordem na Educação. In: ALVES-MAZZOTTI, Alda Judith. Linguagens, espaços e tempos no ensinar aprender. Rio de Janeiro: Agir, 2000.

FAZENDA, I. C. A. Dicionário em construção: Interdisciplinaridade. São Paulo: Cortez, 2001. 
FAZENDA, I. C. A. Interdisciplinaridade: qual o sentido? São Paulo: Paulus, 2003.

FAZENDA, I. C. A. O que é Interdisciplinaridade? São Paulo: Cortez, 2008.

FAZENDA, I. C. A. Integração e interdisciplinaridade no ensino brasileiro: efetividade ou ideologia. São Paulo: Edições Loyola Jesuítas, 2011a.

FAZENDA, I. C. A. Desafios e perspectivas do trabalho interdisciplinar no Ensino Fundamental: contribuições das pesquisas sobre interdisciplinaridade no Brasil: o reconhecimento de um percurso. Interdisciplinaridade, v. 1, n. 1, p. 10. São Paulo: PUCSP, 2011b.

FERNANDES, F. C. R. et al. Subprojeto PIBID-Física da UNIVAP: uma metodologia complementar no ensino não-formal de Física contextualizado pela Astronomia. In: SIMPÓSIO NACIONAL DE EDUCAÇÃO EM ASTRONOMIA- SNEA, 1., 2011, Rio de Janeiro, RJ. Anais [...]. São Paulo: SAB, 2011. Disponível em: https://www.sabastro.org.br/wp-content/uploads/2017/04/SNEA2011_TCP45.pdf. Acesso em: 08 jul. 2021.

FERNANDES, F. C. R. et al. Relato das atividades de extensão e educação nãoformal no ensino de Física e Astronomia realizadas no subprojeto PIBID-Física da UNIVAP. In: SIMPÓSIO NACIONAL DE EDUCAÇÃO EM ASTRONOMIA - SNEA, 2., 2012, São Paulo. Anais [...]. São Paulo: SAB, 2012a. Disponível em: https://www.sab-astro.org.br/wp-content/uploads/2017/03/SNEA2012 TCP52.pdf. Acesso em: 08 jul. 2021.

FERNANDES, F. C. R. et el. O Subprojeto PIBID-FÍSICA da UNIVAP e a formação de professores no ensino de Astronomia e Física. In: SIMPÓSIO DO PIBID/UFABC, 2., 2012. Santo André. Anais [...]. Santo André: UFABC, 2012b. v.1. p.79-82. Disponível em: https://pibid.ufabc.edu.br/ll simposio/resumos/60.pdf. Acesso em: 08 jul. 2021.

FERNANDES, M. T. M. Educação e Poder. 2007. Trabalho de Conclusão de Curso (Pedagogia) - Centro Universitário Claretiano, São José dos Campos, SP, 2007.

FREITAS, G. L.; HALMENSCHLAGER, K. R. Abordagem de temas no ensino de física: o corpo humano como temática contextualizadora. 2014. Trabalho de Conclusão de Curso (Licenciatura em Ciências Exatas) - Universidade Federal do Pampa UNIPAMPA, Campus Caçapava do Sul, 2015. Disponível em: http://cursos.unipampa.edu.br/cursos/cienciasexatas/files/2014/06/TCC GRACIELA. pdf. Acesso em: 02 maio 2021.

FRIGOTTO, G. Interdisciplinaridade como necessidade e como problema nas ciências sociais. In: BIANCHETTI, L.; JANTSCH, A. P. Interdisciplinaridade: para além da filosofia do sujeito. Petrópolis: Vozes, 1995. p. 20-62.

JAPIASSU, H. F. Interdisciplinaridade e patologia do saber. Rio de Janeiro: Imago, 1976. 
KATO, D. S. O significado pedagógico da contextualização para o ensino de ciências: análise dos documentos curriculares oficiais e de professores. 2007. Dissertação (Mestrado em Educação) - Faculdade de Educação, Universidade de São Paulo, São Paulo, 2007.

KATO, D. S.; KAWASAKI, C. S. As concepções de contextualização do ensino em documentos curriculares oficiais e de professores de ciências. Ciência \& Educação, v. 17, n. 1, p. 35-50, 2011. Disponível em:

http://www.scielo.br/pdf/ciedu/v17n1/03.pdf. Acesso em: 13 abr. 2021.

LOPES, A. C.; GOMES, M. M.; LIMA, I. S. Diferentes Contextos na Área de Ciências nos PCNs para o Ensino Médio: limites para a integração. Contexto \& Educação, ljuí, v. 18, n. 69, p. 45-67, 2003. https://doi.org/10.21527/2179-1309.2003.69.45-67.

MACEDO, C. C. Os processos de contextualização e a formação inicial de professores de física. 2013. 187 f. Dissertação (Mestrado Profissional em Ensino de Ciências) - Universidade Federal de Itajubá, Itajubá, 2013. Disponível em: https://repositorio.unifei.edu.br/xmlui/bitstream/handle/123456789/974/dissertacao m acedo 2013.pdf?sequence=1\&isAllowed=y. Acesso em: 20 abr. 2021.

MACEDO, C. C.; SILVA, L. F. Os processos de contextualização e a formação inicial de professores de Física. Investigações em Ensino de Ciências, v. 19, n.1, p. 5575, 2014. Disponível em:

https://www.if.ufrgs.br/cref/ojs/index.php/ienci/article/view/95/66. Acesso em: 15 abr. 2021.

MEC - Ministério da Educação e Cultura. Parâmetros Curriculares Nacionais Ensino Médio (PCNEM): Parte I - Bases Legais, 2000a. Disponível em: http://portal.mec.gov.br/seb/arquivos/pdf/blegais.pdf. Acesso em: 19 abr. 2021.

MEC - Ministério da Educação e Cultura. Parâmetros Curriculares Nacionais Ensino Médio (PCNEM): Parte III - Ciências da Natureza, Matemática e suas tecnologias. Secretaria de Educação Média, Brasília, MEC/SEM, 2000b. Disponível em: http://portal.mec.gov.br/seb/arquivos/pdf/ciencian.pdf. Acesso em: 12 abr. 2021

MEC - Ministério da Educação e Cultura. PCN+ Ensino Médio: orientações educacionais complementares aos Parâmetros Curriculares Nacionais. Ciências da Natureza, Matemática e suas Tecnologias. Brasília: Ministério da Educação, Secretaria da Educação Média e Tecnológica, 2002.

MEC - Ministério da Educação e Cultura. Orientações Curriculares para o Ensino Médio - Volume 2: Ciências da Natureza, Matemática e suas Tecnologias.

Secretaria de Educação Básica. Brasília: Ministério da Educação, Secretaria de Educação Básica, 2006. 135 p. Disponível em:

http://portal.mec.gov.br/seb/arquivos/pdf/book volume 02 internet.pdf. Acesso em: 21 abr. 2021.

MEES, A. A. Astronomia: motivação para o ensino de Física na $8^{a}$ série. 2004. Dissertação (Mestrado Profissionalizante em Ensino de Física). Universidade Federal do Rio Grande do Sul, Porto Alegre, 2004. Disponível em: 
http://www.educadores.diaadia.pr.gov.br/arquivos/File/2010/artigos teses/fisica/disse rtacoes/astronomia.pdf. Acesso em: 8 jul. 2021.

MEES, A. A.; STEFFANI, M. H. Astronomia: motivação para o ensino de Física na $8^{a}$ série. In: SIMPÓSIO NACIONAL DE ENSINO DE FÍSICA - SNEF, 16., 2005, Rio de Janeiro. Anais [...]. São Paulo: SBF, 2005. Disponível em:

https://sec.sbfisica.org.br/eventos/snef/xvi/cd/resumos/T0105-1.pdf. Acesso em: 07 jul. 2021.

MOTA, A. T.; BONOMINI, I. A. M.; ROSADO, R. M. M. Inclusão de temas astronômicos numa abordagem inovadora do ensino informal de Física para estudantes do Ensino Médio. Revista Latino-Americana de Educação em Astronomia - RELEA, n. 8, p. 7-17, 2009. Disponível em:

http://www.relea.ufscar.br/index.php/relea/article/view/135. Acesso em 22 mar. 2021.

NASCIMENTO, T. L. Repensando o ensino da Física no ensino médio. 2010. Trabalho de Conclusão de Curso (Licenciatura Plena em Física). Universidade Estadual do Ceará. Fortaleza, 2010. Disponível em:

http://www.uece.br/fisica/index.php/arquivos/doc details/75-repensando-o-ensino-dafisica-no-ensino-medio. Acesso em: 18 abr. 2021.

RICARDO, E. C. Competências, Interdisciplinaridade e Contextualização: dos Parâmetros Curriculares Nacionais a uma compreensão para o ensino das ciências. 2005. Tese (Doutorado em Educação Científica e Tecnológica) - Universidade Federal de Santa Catarina , Florianópolis, 2005. Disponível em: https://repositorio.ufsc.br/bitstream/handle/123456789/102668/222646.pdf?sequence =1\&isAllowed=y. Acesso em: 19 abr. 2021.

RICARDO, E. C. Problematização e Contextualização no Ensino de Física. In: CARVALHO, A. M. P. (Org.) Ensino de Física: Coleção ideias em ação. São Paulo: Cengage Learning, 2010. Cap.2. Disponível em:

https://edisciplinas.usp.br/pluginfile.php/3461366/mod resource/content/1/capitulo E lio.pdf. Acesso em: 19 abr. 2021.

SANTOS, W. L. P. Contextualização no ensino de ciências por meio de temas CTS em uma perspectiva crítica. Revista Ciência \& Ensino, v. 1, n. esp. 2007.

Disponível em:

https://www.academia.edu/27297895/Contextualiza\%C3\%A7\%C3\%A3o no ensino de ci\%C3\%AAncias por meio de temas CTS em uma perspectiva cr\%C3\%ADt ica. Acesso em: 5 maio 2021.

SILVA, I. B. Uma Pedagogia Multidisciplinar, Interdisciplinar ou Transdisciplinar para o Ensino/Aprendizagem da Física. In: CONGRESSO BRASILEIRO DE EXTENSÃO UNIVERSITÁRIA, 2., 2004, Belo Horizonte, MG. Anais [...]. Belo Horizonte: UFMG, 2004. Disponível em: https://www.ufmg.br/congrext/Educa/Educa173.pdf . Acesso em: 9 abr. 2021.

SIQUEIRA, A.; SILVA, J. B.; CASTRO, A. S. M. Sustentação e direcionamento de aeronaves: Um ensino de física contextualizado. In: SIMPÓSIO NACIONAL DE ENSINO DE FÍSICA, 19.,2011, Manaus, AM. Anais [...]. São Paulo: SBF, 2011. 
Disponível em: $h$ ttps://www2.uepg.br//portaldaslicenciaturas/wpcontent/uploads/sites/14/2019/04/sustentaca-direcionamento.pdf. Acesso em: 5 mai. 2021.

SOUSA, P. S. et al. Abordagem Temática no Ensino de Ciências: diferentes perspectivas e alguns consensos. In: SIMPÓSIO NACIONAL DE ENSINO DE FíSICA, 20.,2013. Anais [....]. São Paulo: SBF, 2013. http://www.sbf1.sbfisica.org.br/eventos/snef/xx/sys/resumos/T0500-2.pdf. Acesso em: 5 maio. 2021.

STADLER, J. P.; HUSSEIN, F. R. G. S. O perfil das questões de ciências naturais do novo Enem: interdisciplinaridade ou contextualização? Ciência \& Educação, v. 23, n. 2, p. 391-402, 2017. Disponível em: http://www.scielo.br/pdf/ciedu/v23n2/15167313-ciedu-23-02-0391.pdf. Acesso em: 19 abr. 2021.

VIZZOTTO, P. A.; MACKEDANZ, L. F.; BUSS, C. S. Contextualização do aprendizado em Física na perspectiva de alunos de curso de primeira habilitação, egressos do Ensino Médio. Experiências em Ensino de Ciências, v. 13, n. 4, p. 226-250, 2018. Disponível em: https://if.ufmt.br/eenci/artigos/Artigo_ID515/v13_n4_a2018.pdf. Acesso em: 10 abr. 2021.

VIZZOTTO, P. A.; MACKEDANZ, L. F. Alfabetização Científica e a Contextualização do conhecimento: um estudo da Física aplicada ao trânsito. Revista Brasileira de Ensino de Física, v. 42, p. e20190027, 2020. Disponível em: https://www.scielo.br/scielo.php?pid=S180611172020000100503\&script=sci abstract\&tIng=pt . Acesso em: 6 maio. 2020.

WARTHA, E. J.; ALÁRIO, A. F. A contextualização no Ensino de Química através do Livro Didático. Química Nova na Escola, n. 22, p.42-47, nov., 2005. Disponível em: http://qnesc.sbq.org.br/online/qnesc22/a09.pdf. Acesso em: 20 de abril 2021. 